-HIGHER-

EDUCATION

-POLICY-
Higher Education Policy, 2007, 20, (117-119)

(C) 2007 International Association of Universities 0952-8733/07 \$30.00 www.palgrave-journals.com/hep

Editorial

\title{
The Travel of Ideas
}

Higher Education Policy (2007) 20, 117-119. doi:10.1057/palgrave.hep.8300153

This issue of Higher Education Policy contains five contributions that deal with developments in China and Japan. The Forum contribution deals with a comparison between China and Australia. Obviously, we are travelling to the east (and to the south) - at least from the perspective of the International Association of Universities' headquarters or the perspectives of the editor's country of residence. About 740 years ago, Marco Polo was one of the first documented travellers to connect the Western World and the Far East, and now we witness an increasing interest in developments in China and other countries in that region. Obviously, the political opening up of many of the nation-states and their booming economies play a considerable role in the increasing scholarly curiosity in higher education, either as a socio-cultural or an economic phenomenon.

The reference to Marco Polo is deliberately chosen, for his travels were not simply meant to bring stories from the East to the West. On the contrary, the travels were cultural exchanges, both meant to inform the ruler (the Pope) back home and to inform the leaders in the East (in casu the Kublai Khan) about developments in the Western World and other regions. The same can be said about the contributions to this issue: the papers evidence a fruitful exchange of concepts and ideas across national and cultural barriers.

Su-Yan Pan's paper deals with the state-university interface from a historical perspective. Her case study is one of the prestigious universities in China, the Tsinghua University. Addressing three specific episodes in the university's history, she sets out the power dynamics that played a dominant role in the relationship between government and the university. What becomes clear is that a strong state not necessarily implies a low level of institutional autonomy: there proved to be considerable leeway for negotiation throughout the university's history, partly thanks to the personal skills of the university's leadership in dealing with government officials. The paper is a good illustration of the exchange idea set out above, for the theoretical underpinnings of the paper are derived from the Western higher education literature on autonomy. At the same time the empirical findings give input to a reconsideration of the Western expectation that recruitment of scholars into government positions in which the party doctrine plays a considerable if not dominant role, would bring universities in a situation of great dependency and low levels of autonomy. 
The article by Manhong Lai and Leslie Lo addresses changes in the Chinese academic profession. In a situation of scarce resources, due to the expansion of the system, and of increasing state intervention (through requiring universities to present staff quality reports and by reforming human resource systems), the authors argue that certain trends of deprofessionalization are visible. Although the empirical support is limited - eight interviews within a particular university - the in-depth analysis is revealing. The analysis carefully delineates the consequences of the government policies. Like Su-Yan Pan's article, this paper draws heavily on the Western literature. But, at the same time, the paper is able to address and integrate the indigenous phenomenon of quanxi. This phenomenon - roughly to be interpreted as a Chinese version of the concept of social capital - plays a considerable role in the context of the academic profession. Academics who have been able to secure their position in the disciplinary networks were able to manipulate that network to some extent, but younger scholars were confronted with the challenge to either play the quanxi game and lose some of their level of freedom or to be independent with the risk of not being able to secure resources for their independent ideas.

Quanxi also plays an important role in Li and Van Baalen's contribution. The authors set themselves the task of exploring how management education indigenized in Chinese higher education. Without exaggeration it can be said that management education in China is big: almost 2.5 million students are enrolled in management programmes at about 1,400 higher education institutions. These institutions seem to struggle with the dilemma of the extent to which management programmes should (and can) be informed by Western and indigenous management concepts. The small-scope empirical research presented focuses on the content of programmes, the legitimization of (MBA) education and the indigenization of pedagogy. Particularly regarding the legitimization aspect, the authors are able to show the impact of management education on quanxi networks. The promising theoretical framework is an invitation to scholars to broaden the empirical basis, not necessarily addressing solely management education or China, but possibly also the phenomenon of indigenization in higher education in other fields and/or countries.

In contrast to the Chinese system, the Japanese higher education system has a much longer history of being studied, both by foreign and indigenous scholars. Part of the explanation is, of course, that the country was much more accessible for scholars interested in Japanese higher education. For instance, Japan joined the OECD in 1964 and its higher education system as such was in many respects considered - despite huge cultural differences - as a Western system. Scholars were particularly interested in how the balance between the relatively small share of public and the huge private sector and the rather steep hierarchy of institutions would work out in terms of , foe example, access to higher education. In Masahiro Tanaka's paper on the transition of legal 
education in Japan from a competitive to a qualifying bar examination, it becomes clear that the recent developments in Japanese law schools are influenced by the US law school system as well as by comparisons of numbers of inhabitants of the nation state per legal professional across other large countries (US, Britain, Germany, France).

The final contribution is in the Forum section. Shengrong Chen's contribution compares trends in Australian and Chinese higher education, highlighting some interesting similarities and differences between the countries' evolutions.

Jeroen Huisman 